\title{
Feasibility Four Ways
}

DOI:

$10.1017 / \mathrm{S} 0265052517000103$

\section{Document Version}

Accepted author manuscript

Link to publication record in Manchester Research Explorer

\section{Citation for published version (APA):}

Hamlin, A. (2017). Feasibility Four Ways. Social Philosophy and Policy, 34(1), 209-231.

https://doi.org/10.1017/S0265052517000103

\section{Published in:}

Social Philosophy and Policy

\section{Citing this paper}

Please note that where the full-text provided on Manchester Research Explorer is the Author Accepted Manuscript or Proof version this may differ from the final Published version. If citing, it is advised that you check and use the publisher's definitive version.

\section{General rights}

Copyright and moral rights for the publications made accessible in the Research Explorer are retained by the authors and/or other copyright owners and it is a condition of accessing publications that users recognise and abide by the legal requirements associated with these rights.

\section{Takedown policy}

If you believe that this document breaches copyright please refer to the University of Manchester's Takedown Procedures [http://man.ac.uk/04Y6Bo] or contact uml.scholarlycommunications@manchester.ac.uk providing relevant details, so we can investigate your claim.

\section{OPEN ACCESS}




\title{
Feasibility Four Ways
}

\author{
Alan Hamlin \\ University of Manchester \\ and \\ King's College London
}

\begin{abstract}
Both the idea of feasibility and the role that it might play within political theory are controversial. Recent discussions have attempted to specify an appropriate overall conceptualization of feasibility. This paper offers a more nuanced account of a number of inter-related aspects of feasibility and argues for a more realistic view of feasibility. Four aspects of feasibility are identified and discussed: resource feasibility, value feasibility, human feasibility and institutional feasibility.
\end{abstract}

\section{Keywords}

Feasibility, Resources, Values, Motivation, Institutions.

\section{Acknowledgements}

Earlier versions of this paper have benefited from discussion by audiences in Manchester, London and Montreal, I particularly thank Geoffrey Brennan, Kimberley Brownlee, Richard Child, Jerry Gaus, Mike Munger, Mark Pennington, Miriam Ronzoni, Zofia Stemplowska, Jo Wolff and the editor and anonymous referees for this journal for their helpful comments. 


\section{Introduction}

At least a major part of the political debate may be construed in terms of the interaction of criteria of desirability with issues of feasibility. While the analysis of desirability occupies the greater part of political philosophy, issues of feasibility often bear the majority of the burden in more practical settings. The eradication of some disease is surely desirable, but is it feasible? A world in which the life expectancy of all new-born children is roughly equal may be desirable, but is it feasible? A global political consensus on the treatment of refugees is desirable, but is it feasible? And what issues are raised by questioning feasibility in such cases?

Analytic interest in the feasibility side of political debate has developed recently with several attempts at providing a definitional conceptualization that captures the essence of the idea of feasibility. ${ }^{1}$ The main line of this recent literature is the conditional probability account of feasibility. ${ }^{2}$ Although there are differences of detail between authors, the development begins from an intuitive statement such as, "Very roughly, some state of affairs is feasible if there is a way we can bring it about" (Gilabert and Lawford-Smith, 2012, p.809) and then refines this statement to account for various criticisms until we reach:

"Our development of the concept of feasibility allows us to state two feasibility tests, as follows:

Test 1/Binary: It is feasible for $\mathrm{X}$ to $\Phi$ to bring about $\mathrm{O}$ in $\mathrm{Z}$ only if $\mathrm{X}$ 's $\Phi$-ing to bring about $\mathrm{O}$ in $\mathrm{Z}$ is not incompatible with any hard constraint.

Test 2/Scalar: It is more feasible for $\mathrm{X}$ to bring about $\mathrm{O}_{1}$ than for $\mathrm{Y}$ to bring about $\mathrm{O}_{2}$ when it is more probable, given soft constraints, for $\mathrm{X}$ to bring about $\mathrm{O}_{1}$ given that he 
or she tries, than it is for $\mathrm{Y}$ to bring about $\mathrm{O}_{2}$ given that he or she tries". (Gilabert and Lawford-Smith, 2012, p 815).

Where $\mathrm{X}$ and $\mathrm{Y}$ are agents, $\Phi$ is an action, $\mathrm{O}, \mathrm{O}_{1}$ and $\mathrm{O}_{2}$ are outcomes and $\mathrm{Z}$ is a description of the relevant context.

This account focuses on agents (individual and corporate) and distinguishes between binary or categorical and scalar or continuous forms of feasibility and invokes a number of further ideas, most obviously the distinction between hard and soft constraints and the idea of an agent 'trying' to achieve the relevant outcome. A hard constraint is one that cannot be breached and is always and everywhere relevant, while a soft constraint is one that may apply to some degree and may vary from circumstance to circumstance; the idea of 'trying' is introduced to rule out cases where some particular human motivation is required but where it seems inappropriate to describe an action as infeasible just because the relevant motivation is not (sufficiently) present.

While this account is plausible, it might be said to pass the difficulties regarding feasibility on to the more detailed discussion of hard and soft constraints and the idea of 'trying'. The distinction between hard and soft constraints may seem clear enough, but there are many types of each form of constraint and it is not clear that they all play similar roles. The idea of an agent 'trying' requires much further consideration. It might also be said that this approach to feasibility focuses on what I will term the case of absolute feasibility - a conception of feasibility that is itself somewhat idealized. In what follows I will argue for the recognition of a more relative notion of feasibility that pays greater attention to reality.

Wiens is somewhat critical of the Gilabert and Lawford-Smith approach and, in particular, their treatment of agent motivation. ${ }^{3}$ He offers an alternative restricted possibility account of feasibility based on an extension of the economists' idea of a production possibility frontier to include all 
forms of constraint whatever their origin. I will discuss this account in more detail below but for now it is sufficient to note that Wiens treats all forms of feasibility constraint as being essentially similar.

This paper aims both to add detail to the discussion of feasibility offered in the conditional probability and restricted possibility accounts of feasibility and to offer a more realistic rendering of feasibility. Detail will be added by shifting the focus away from the attempt to provide a single comprehensive definition of the concept of feasibility and towards a more fine-grained account of the internal structure of the idea of feasibility, arguing that there are several inter-related aspects of feasibility relevant to political theory. In particular, I offer an account of four aspects of feasibility and their inter-relations: resource feasibility, value feasibility, human feasibility and institutional feasibility. These aspects may be thought of as identifying sub-domains of constraint which cut across the distinction between hard and soft constraints. Within each of these subdomains I will explore the distinction between absolute and relative notions of feasibility and suggest that a relative notion is more appropriate if we wish to connect the idea of feasibility more directly to the circumstances that obtain in the real world. Just as I suggest that feasibility is best understood in terms of a number of aspects, so I suggest that the distinction between absolute and relative notions of feasibility has several dimensions. I will emphasize an epistemic dimension in what follows, but other dimensions will also be introduced particularly in relation to human and institutional feasibility. The general point is that by recognizing both the various aspects of feasibility and the distinction between absolute and relative feasibility within each aspect, we can enrich our understanding of overall feasibility.

My primary intention here is not to engage in a direct critique of either the conditional probability or the restricted possibility accounts of feasibility, but rather to develop a more detailed account 
of feasibility that, I believe, shows the distinction between the two accounts of feasibility to be relatively minor. I will suggest that the analysis offered here provides a more detailed and more realistic framework for the idea of feasibility: one that is capable of identifying a number of issues that tend to be obscured by more summary and abstract approaches.

Before sketching the four aspects of feasibility, I need to make three preparatory remarks. First, I emphasize that I do not propose these four aspects of feasibility as identifying different, still less competing, conceptions of feasibility. Neither do I suggest that the identified aspects are separable; indeed I stress their inter-relatedness. The terminology of 'aspects' signals the intention to identify these aspects as being joint constitutive parts of a complex overall concept of feasibility.

Furthermore, I do not claim that the four aspects identified offer the only way of analyzing the concept of feasibility. It may be that different or additional aspects can be isolated. Different analyses may be useful in different contexts. The main point is that analyzing out aspects of feasibility and exploring the distinction between absolute and relative feasibility can contribute to our understanding in ways that may be obscured by focusing all our attention on a comprehensive formulation.

Second, ideas of feasibility may be taken to apply to (at least) any one of: specific actions, strategies seen as composite actions undertaken by a single agent, sets of actions or strategies involving many agents, specific events or outcomes, time-slice statements of the state of the world, or complete inter-temporal states of the world. In everyday usage, and some academic debate, we slip between these possibilities and this may not be problematic in at least some cases. While the distinctions between resource, value, human and institutional feasibility are largely independent of the arena of application, it may still be the case that there are significant issues at 
stake in moving from arena to arena. For example, if we focus on the feasibility of specific actions by individual agents we might conclude that each of several actions under consideration is feasible, but it might still be the case that these actions are not co-feasible in the sense that they cannot all be undertaken: taking one action (or some combination of actions) may render some other action, that is entirely feasible in isolation, infeasible. Focusing on act-by-act feasibility will tend to miss issues of co-feasibility, which are nevertheless genuine issues of feasibility. The focus on co-feasibility rather than act-by-act feasibility will be a theme running through the discussion.

Third, as already mentioned, feasibility may be analyzed either in terms of the categorical distinction between the feasible and the infeasible or in terms of degrees of feasibility. I interpret the latter approach as encompassing the former in the sense that we may maintain the idea of degrees of feasibility without dispensing with the limiting case of categorical infeasibility.

\section{Resource Feasibility}

Perhaps the most intuitively accessible notion of feasibility is the idea that any state of the world makes demands on underlying resources and that only states of the world where these demands are co-possible can be declared feasible. ${ }^{4}$ At the most abstract level, we might consider the idea of absolute resource feasibility as deriving from hard physical constraints and the true laws of science, whatever they may be. If the world is characterized by fixed quantities of certain basic resources (such as chemical elements) and physical laws concerning the technologies by which these resources may be transformed into each other or into more complex items, then these basic facts constrain the set of resource feasible states of the world. Note that the idea of resource feasibility here includes the notion of technological feasibility, since technology (the means of 
transforming resources) is itself a resource. At a more practical level, we might consider the idea of relative resource feasibility. The most obvious dimension of the distinction between the absolute and relative notions of resource feasibility is the epistemic, so that relative resource feasibility is relative to some particular state of knowledge regarding available resources and technology at any particular time; so that, for example, space flight would be viewed as relatively infeasible in the early twentieth century (even though it was absolutely feasible) but both absolutely and relatively feasible by the late twentieth century as a result of epistemic advances.

The logic of the idea of resource feasibility is similar for both the absolute and relative cases. Beginning with the set of resources known (or believed) to exist, and the set of techniques for combining these resources to make other items, we can identify a range of feasible production plans. A production plan identifies a set of outputs that may be produced from the given inputs and technology. Clearly there are many possible production plans for any set of resources and technology - each identifying a co-feasible set of outputs. The set of all such production plans relating to any particular stock of inputs and technology constitutes the production possibility set. The production possibility frontier forms the boundary of that set, providing both the categorical distinction between those combinations of things that are resource feasible and those that are not, and an illustration of the degree of resource feasibility by indicting the extent of spare capacity implied by any production plan that lies strictly within the frontier. Note that the idea of a production possibility frontier focuses attention on states that are feasible, deriving from a set of productive actions that are co-feasible, rather than the feasibility of particular productive actions taken in isolation.

The idea of resource feasibility (whether absolute or relative) may be developed in either static or dynamic modes: in static mode we are concerned with the resource feasible options at a moment 
in time with any trade-offs along the frontier representing the opportunity costs inherent in the limited nature of resources and technology; in dynamic mode we are concerned with resource feasible paths through time taking additional account of any interdependencies that there may be between resource use in one period and resource use in other periods (for example, if certain productive processes are irreversible, or reversible only at significant resource cost). ${ }^{5}$

The distinction between absolute and relative resource feasibility is largely an epistemic one, concerned with what resource stocks and technologies are understood to be accessible to a given population at a given point in time, and how the processes of discovery and technical progress depend upon particular actions chosen. The debate over recent decades concerning estimates of the quantity of accessible oil in the world provides an example of the way in which a relative resource feasibility 'constraint' may change significantly over even short periods of time. Similar epistemic dimensions of other aspects of feasibility to be discussed below will point to the fact that epistemic issues overlay most discussions of feasibility. However, we will also see that other dimensions of the distinction between absolute and relative feasibility may be important in relation to other aspects of feasibility.

While the idea of absolute resource feasibility places a hard (if possibly unknowable) constraint on what can be done, the idea of relative resource feasibility bears more interestingly on many issues of social policy. Some desired policy action or outcome may be resource infeasible given the current state of knowledge, but we may not think that this state of affairs is permanent. Consider the relative infeasibility of eradicating some disease when no relevant vaccine has been discovered, but where such a discovery is considered possible in the future. In such circumstances, we might think that the desirability of relatively infeasible outcomes would help to set research priorities; devoting resources to medical research, for example, even if the resource costs of such 
research makes it impossible to pursue other desirable activities. This last point illustrates the general idea of the required co-feasibility of the set of all actions; and the trade-offs that arise between actions, including actions designed to expand the feasible set.

This basic idea of resource feasibility links directly to the discussion of feasibility by Wiens who emphasizes that his restricted possibility account of feasibility amounts to a generalization of the idea of a production possibility frontier, a generalization that effectively treats everything as a resource. ${ }^{6}$ Relative to this position, I suggest that maintaining the distinction between non-human resources and technology in the narrow sense employed here on the one hand, and other more social aspects of feasibility, including issues of human effort, motivation and institutional structure, on the other hand, provides a finer grained understanding of the complexity of the idea of feasibility. One particular benefit of maintaining this distinction relates to the identification of interactions between normativity and feasibility.

The narrow idea of resource feasibility advanced here is, in principle, separable from normative considerations. By this I mean no more than we do not need to specify any particular normative principles, or any particular criteria by which those principles might be brought to bear on evaluation or justification, in order to address and potentially answer questions of either absolute or relative resource feasibility. And our answers to those questions will stand whatever normative principles and criteria we might develop. It might be objected that it may be a normative matter what we consider to be a resource in the first place. For example, are animals merely resources? Indeed it may be the case that some normative significance attaches to at least some of the things that we identify as resources, and that such normative significance will imply additional feasibility constraints, but I suggest that any such additional constraints are better treated under the heading of value feasibility. 


\section{Value Feasibility}

While the issue of resource feasibility is what is at stake in some contexts, at least some questions of feasibility important in political debate relate more directly to the feasibility of realizing particular values or combinations of values, or of achieving outcomes while respecting particular values. We might ask, for example, whether a social outcome that is both fully egalitarian and consistent with an acceptable degree of personal freedom is feasible. Or if a particular outcome is feasible while respecting particular norms (for example, treating animals appropriately). Such questions cannot be answered solely by reference to the idea of resource feasibility. Answers will depend on much finer grained specifications of what we mean by 'a fully egalitarian outcome', 'an acceptable degree of personal freedom', and 'treating animals appropriately' but even when we have provided such specifications, we may recognize three distinct ways in which the feasibility issue might be decided. First, it might be the case that values constrain each other: that there is something in our understanding of relevant values that entails some degree of conflict between them. The idea of irreducibly plural values and the potential for conflict is well established, if contentious. ${ }^{7}$ The point here is simply that any such value conflict amounts to identifying some combinations of values as infeasible. It might be suggested that such conflict among values is not best viewed as a matter of infeasibility, with the issue of feasibility limited to the realm of the conceptually possible. However, there is a clear analogy with the idea of resource feasibility: just as it seems appropriate to treat the possibility of realizing physical states of the world as a matter of feasibility/infeasible, so it seems appropriate to treat the possibility of realizing combinations of values as a matter of feasibility/infeasibility. 
Second, it might be the case that resources constrain values: even if values do not themselves conflict, it might be that issues of resource feasibility imply at least some value infeasibility insofar as the achievement of certain combinations of value might require outcomes that are not resource feasible. And this point applies equally to the ideas of human and institutional feasibility to be discussed below - the achievement of any particular value combination may be rendered infeasible if it depends upon achieving outcomes that are themselves infeasible in any of these senses.

Third, it might be that values constrain outcomes directly: so that respecting a particular value or values renders some otherwise feasible outcome infeasible so that normative considerations act as side constraints the set of outcomes that are value feasible even if a wider set of outcomes are feasible in the resource, human and institutional senses. For example, treating animals appropriately may constrain our ability to produce some outcomes that would be feasible if animals were treated as mere resources.

As with the idea of resource feasibility, we can distinguish between absolute and relative notions of value feasibility by reference to an epistemic dimension, with absolute value feasibility referring to the situation of full and perfect information and relative value feasibility referring to more realistic situations with epistemic limitations. These limitations may concern our understanding of the values themselves (or the appropriate ways in which values can be combined or traded-off against each other) or may be imported from the resource, human or institutional arenas.

Just as the idea of resource feasibility addresses the issue of what is physically achievable (either in the absolute sense or relative to some more realistic epistemic state) so the idea of value feasibility addresses the issue of what is morally achievable. We might think of resource and value feasibility as defining what we mean by resources, production techniques and values (either 
absolutely or relative to some epistemic state) and recognizing that we live in a condition of generalized scarcity.

Obviously value feasibility, unlike resource feasibility, is not separable from notions of normativity - it depends directly on a specification of relevant values and an ability to evaluate states of the world in terms of those values. However, as with the idea of resource feasibility, we may conceive of value feasibility in either static or dynamic contexts, so that the idea of value feasibility may be employed in terms of the potential opportunity costs associated with the realization of values at a moment in time, or with the path to states realizing combinations of values over time.

\section{Human Feasibility}

The human aspect of feasibility then relates to the question of what, if any, further feasibility constraints are added, over and above those of resource and value feasibility, when we consider that states of the world must be brought about, in part, by human agents.

Begin with a rough distinction between human physical limitations and human motivational limitations. We might, for example, think it physically infeasible for any human to run 100 meters in, say, 5 seconds, while we might think that, for at least many individuals, any claim that running 100 meters in, say, 50 seconds is infeasible would simply betray a lack of motivation rather than any genuine physical inability. Gilabert and Lawford-Smith accept this distinction and the idea that while an action may be infeasible if it requires more human physical effort than is available, a lack of appropriate or sufficient motivation should not be treated as rendering an action infeasible, "The fact that people do not want to do something does not mean that we should think 
getting it done is infeasible, it just means we should think about how to change incentive structures and thereby change people's desires." (Gilabert and Lawford-Smith, 2012, p.813).

To investigate this idea further, put aside, for the moment, the reference to 'incentive structures' and changing people's desires (which will be taken up in the next section) and return to the idea of 'trying'. Staying with the athletic example, what might it mean to 'try' to run 100 meters in, say, $\mathrm{N}$ seconds? I have already suggested that there might be some values of $\mathrm{N}$ (such as 5) where we might consider this task physically infeasible whatever we mean by 'trying' but, in more moderate cases, our understanding of 'trying' will be crucial in deciding the feasibility issue. At the relaxed end of the spectrum we might understand 'trying' to mean simply engaging fully with the enterprise at the relevant time: I would be 'trying' in this sense if, on the day of the 100 meters time trial, I fully intend to run as fast as I can and maintain maximum effort over the full course. At the more stringent end of the spectrum we might understand 'trying' as requiring a full commitment to the project over an extended time period: I would be 'trying' in this sense only if I dedicate myself fully to sprint training over a long period. What degree (and duration) of dedication to the project is required, if I am to pass the relevant test of 'trying'?

A debate between Estlund and Wiens is relevant here. ${ }^{8}$ Roughly, Estlund aims to refute what he terms the 'human nature constraint' and argues that 'no (non-pathological) motivational incapacity' should be such as to render the relevant action infeasible. Wiens challenges this argument and suggests that where actions are subject to 'failed repeated good faith efforts' we should regard those actions as infeasible. To be clear, both Estlund and Wiens accept the idea of human physical infeasibility; there are some things that humans, or particular humans, simply cannot do regardless of motivation and how hard they try. The nature of the debate between them is where, if at all, on the spectrum of 'trying' we should locate the threshold of distinctively 
motivational infeasibility, ${ }^{9}$ and the debate between them focuses on the distance between the 'failed repeated good faith effort' and the 'pathological'. In terms of our athletic example, I understand Wiens's 'failed repeated good faith effort' approach to say that if, and only if, after many periods of intense and appropriate training, and many attempts at the time trial, an individual's personal best remains significantly above $\mathrm{N}$ seconds, we should declare the task infeasible. I understand Estlund's 'no (non-pathological) motivational incapacity' approach to say that if, and only if, the act of trying to run 100 meters induces in the individual a pathological reaction that makes the achievement of a time of $\mathrm{N}$ seconds physically impossible, we should declare the task infeasible.

This debate seems to depend on the precise location of the distinction between the physical and the motivational. If motivation is a form of mental attitude we must recognize that motivation may not be the only ingredient of 'trying'. Our 100 meters example illustrates the point that temporal and physical (human and non-human) resources may also be involved in 'trying', and these may be subject to resource feasibility constraints. This may be what Wiens has in mind in relation to 'repeated good faith efforts'; it seems that what is meant by 'good faith' is precisely that the appropriate mental attitude is indeed in place, so that, presumably, the repeated failure lies in the translation from motivation to action via other aspects of 'trying'. Estlund's idea of 'no nonpathological motivational incapacity seems more tightly focused on the potential incompatibility between the relevant motivational mental attitude and the individuals own physical ability to act. In these terms, the difference between the two positions seems relatively slight - each suggests that a simple lack of the relevant motivational attitude cannot in itself provide the basis for a claim of infeasibility. While the debate operates in terms of identifying the trigger point for a categorical notion of feasibility - the boundary between the feasible and the infeasible, we might reinterpret 
the debate in terms of degrees of feasibility, with the degree of feasibility related monotonically to the degree of 'trying'.

I want to stress two rather different points here. First, the athletic example - like the examples used by Estlund and Wiens (which include writing a book and climbing a ladder) - focus on the feasibility of a specifically identified task. But, as already stressed, we are concerned not only with the feasibility of the completion of some specified task but the co-feasibility of a range of actions that would jointly bring about a target state of affairs. It might well be that each of the several tasks under consideration, taken in isolation, is humanly feasible in a straightforward sense, but that it is still infeasible for the individual in question to achieve all of the required tasks and so achieve the relevant state of affairs. In particular, this may be because the level of 'trying' associated with each task may be such as to cumulatively exhaust the individual's overall capacity. If it is feasible for me to run 100 meters in $\mathrm{N}$ seconds only by devoting myself to the training regime of a full-time athlete, this will in itself restrict my ability to devote similar levels of 'trying' to the achievement of other tasks. This is not to say that there is some mysterious 'quantity of motivation' that must be allocated across tasks, but rather to say that motivation often operates through dedicated time consuming effort and the use of other resources - and that the physical and temporal aspects of such efforts are necessarily subject to scarcity. While this simple point retains the focus on the physical aspects of 'trying' rather than pointing to any purely motivational infeasibility, it shifts attention away from the human feasibility of individual actions and toward the human feasibility of overall states of the world and the co-feasibility of the sets of actions that support any given state, and in this context it seems entirely plausible that limits on the capacity for 'trying' may impose specifically human feasibility constraints. 
My second point relates to the distinction between absolute and relative human feasibility. Here I extend the discussion of the dimensions relevant to the distinction between the absolute and relative which is intended to pick out the difference between ideal and more realistic perspectives. In an ideal world one might specify that all individuals fully comply with all appropriate moral norms, but in a non-ideal world while moral and social norms may still play a role in individual motivations alongside individual interests and other considerations, these norms may reflect idiosyncratic beliefs about what morality requires and may be internalized to different degrees, so that motivational mental attitudes themselves will vary from individual to individual and often fall short of any ideal moral standard. Moral realists would argue that such differences in moral beliefs are best understood in epistemic terms - as partial or incomplete knowledge of the true morality. Those who reject moral realism would argue that such pluralism about morality may be more basic and is not 'merely' epistemic.

An absolute version of human motivational feasibility is idealized in the sense that it takes any motivational attitude to be feasible if it is not impossible for a human being to hold that attitude. In other words, it would not identify any issue relating to the variety of actual human motivation or moral beliefs, or any difficulties that might be faced in shifting from one motivational stance to another, as providing grounds for a claim of human infeasibility based on motivational rather than physical limitations. The basic point, on this view, is essentially that attributed to Estlund and Wiens; there can be no claim that an act is infeasible just because the individual lacks the relevant motivational attitude.

A relative version of human feasibility would suggest that an act is (relatively) infeasible if it cannot result from the set of motivational attitudes currently in place or from a set that can plausibly be attained from the current set, by a process that is itself feasible. Where the reference 
to the motivational attitudes currently in place identifies a static notion of relative human feasibility, while the reference to motivational attitudes that can be plausibly attained from those currently in place identifies a dynamic notion of relative human feasibility. In each case, the underlying issue may be, at least in part, epistemic, to the extent that it derives from a lack of knowledge or understanding of truly appropriate attitudes; but may also go beyond the epistemic into matters of moral psychology. The dynamic formulation of relative human feasibility focuses particular attention of the processes that might lead motivational attitudes to change, and the plausibility (and costs) of such change, whereas the absolute approach to human feasibility tends to obscure these issues. Amongst the mechanisms that we might expect to exert some influence on motivations are the institutional arrangements within which individuals act, and the possible incentive effects associated with these institutions.

A further possible source of human feasibility constraints arises out of the distinction between individual and collective agents. Gilabert and Lawford-Smith are clear in their aim of including collectivities in the set of agents to which their account of feasibility applies. ${ }^{10}$ While much of the debate focuses on individual humans and the interpretation of 'trying', we should also be concerned with the issues arising in relation to collective agents. The very idea of group agency, as well as its potential significance, is contentious. ${ }^{11}$ But we need not take a position on that issue here; we can simply note that a variety of types of groups exist in the political world ranging from informal groups which almost certainly fail any relevant test for the status of agency, to formal institutions which will be identified as agents by some but which will be recognized as politically salient by all. Examples of the latter type include political parties, firms, and the state itself. The interaction between individual agents and such institutions and the possibility of distinctively institutional aspects of feasibility will be considered in the next section. 
How does including at least some groups in the set of agents influence our understanding of agent feasibility? One obvious point here relates to the simple existence of the relevant group. Some desirable act might be entirely feasible if, and only if, a particular group of individuals comes together to perform that act. In the absence of the particular group, the act would be infeasible. So the question is then, is it feasible to form the group? If we take an absolute view of feasibility, and all the relevant individuals exist, we would conclude that forming the group is feasible and therefore the act that depends on the group's existence is feasible. However on a relative view of feasibility, we might recognize epistemic and other barriers to the group actually forming including the demands of the roles of the relevant individuals in other groups, epistemic issues relating to the understanding of the necessity of the group, and so on - and we might reasonably think that such barriers should be recognized as soft constraints that may render the formation of the group less than fully feasible.

Tomlin raises further doubts relating to the relative feasibility of group action by arguing that the ability of a group to act may depend on each individual member playing their part, and that if, as a matter of fact, it is known that some of the members of the group are not motivated to play their part, then it will be infeasible for the group to act; as he puts it, "individual won'ts lead (in some sense) to collective can'ts". ${ }^{12}$

If we take the set of agents to include groups as well as all individuals and adopt an absolute idea of human feasibility, it would seem that the only additional feasibility constraints introduced by considering the human aspect of the world are those associated with physical human limits, so that this account of feasibility would render humans on a par with physical resources and merely include their physical limits alongside other resource feasibility constraints. This would seem to be the position taken, to slightly differing degrees, by Gilabert and Lawford-Smith, by Wiens and 
by Estlund. ${ }^{13}$ In order for there to be a distinctively human feasibility constraint we must either take a more relative position which attends to motivations as they actually are, or as they might reasonably be expected to become through some attainable process of change, rather than as they might, or should, be; or interrogate further the relationship between individual and collective agents or institutions.

Human motivations are often normative in the sense that they reflect, or otherwise respond to, normative beliefs. Indeed, it is an essential feature of most ideas of normativity that norms should be action-guiding and the most direct route for such action guidance is via motivation. While issues relating to human physical abilities might be seen to be independent of normative concern, so that purely physical human abilities might be viewed as a resource alongside other resources; human motivational issues, including issues associated with the plurality of imperfect normative beliefs that underlie human motivations, will generally be normative in character. Again, there is no clean separation between issues of desirability and issues of feasibility.

\section{Institutional Feasibility}

The analysis of political and social institutions is central to almost all conceptions of political theory. And this fact alone is sufficient to point to the advantage of identifying institutional feasibility as a distinctive aspect of the overall conception of feasibility - it allows us to focus on the design and reform of political and social institutions and their potential role in modifying motivations and therefore behavior, from the perspective of feasibility, holding other aspects of feasibility constant. 
One way of thinking about these issues refers back to the idea of technology. Recall that in discussing resource feasibility it was necessary to take a view on the production technologies available for transforming fundamental resources into potentially valuable things. By analogy, we might think of institutional arrangements as a form of social technology. The basic point here is that in order to establish institutional feasibility we have to take several additional steps: first we must specify a particular institutional arrangement that we believe to be feasible in itself, then we have to analyze the operating characteristics of that institutional arrangements together with its incentive effects on human motivations in order to come to a view as to the likely implications of adopting that institutional arrangement for the states of the world to be realized. In the first step we need to focus on what makes an institutional arrangement feasible in itself; here it must be recognized that institutions are costly in the sense that they use (human and non-human) resources, but a second and significantly different sense of feasibility in relation to institutions is that they must relate appropriately to human motivations. The point to stress here is the dual nature of the relationship between institutions and human motivations. On the one hand, institutions must be operated by agents acting under their own motivations while, on the other hand, one of the key roles of institutions is to provide a framework of incentives and other features that condition and modify individual motivations. We might think of an outcome emerging under an institutional framework when the motivations realized and supported under that institutional framework lead to individual behavior within that institutional framework that, in turn, generates the particular outcome.

In analyzing the operating characteristics of any feasible institutional arrangement we will need to employ the ideas of resource feasibility, to ensure that the institutional arrangement in question is operating within the relevant resource and technological constraints, and of value feasibility, to 
facilitate the comparative evaluation of alternative institutional arrangements given the appropriate specification of values, and of human feasibility to account for any incentive effects arising from the institutional structure in question.

In this way, the idea of institutional feasibility may be thought of as requiring theorems on the characteristics of alternative institutional arrangements which build on the ideas provided by the notions of resource, value and human feasibility.

The idea of institutional feasibility focusses attention on the operating characteristics of alternative institutional arrangements and the states of the world that might be expected to be realized under those arrangements, or, to put the same point in other words, focusses attention on the motivations and behavior of individuals, how these motivations and behavior might be shaped and conditioned under different institutions, and how the actions of individuals combine through institutional structures to determine outcomes.

As with the resource and value aspects of feasibility, institutional feasibility may be conceived in either absolute or relative terms. In this case, the distinction relates to the specification of the institutional structure in question and the motivation and behavior of agents within that institutional structure. In this sense, the standard economists' fundamental welfare theorem that shows that, in principle, a full set of perfectly competitive markets operated by fully rational individuals will produce an outcome that is Pareto optimal, may be considered to lie at the absolute end of the spectrum since it makes no concessions to reality in specifying either the institutional structure under investigation or the agents that populate that structure. ${ }^{14}$ By contrast, Von Mises's and particularly Hayek's arguments for the infeasibility of socialism invoke a relative notion of feasibility and hinge on an analysis of central planning's institutional inability to operate in a 
setting in which information is necessarily distributed across agents rather than (costlessly) accessible to all. ${ }^{15}$ The key idea here is again broadly epistemic. A further example of the use of a relative notion of feasibility in the discussion of institutional design is provided by Pennington who argues that the robustness of the operation of market institutions in non-ideal circumstances provides a key argument in their favor. ${ }^{16}$

The idea of relative institutional feasibility is further illustrated by a popular usage of the terminology of 'political infeasibility'. ${ }^{17}$ We commonly hear that, in a country torn by civil war, peace is 'politically infeasible', or, less dramatically, that compromise between political parties in a democracy such as the US or the UK is 'politically infeasible'. I take it that what is normally meant by such statements is that the history of the situation and of the agents involved is such that the various parties have committed themselves to positions which do not allow of a resolution of the issue at hand, at least in the short or medium run, even though such a resolution is available from an absolute perspective. The situation, in short, is that politics is seen as the problem, rather than the solution.

We might suggest that the particular path taken by events has led, through steps which were not necessarily intended to have this effect, to an impasse where the institutional structures that characterize politics are unable to perform the role that is generally expected of them. Of course, other accounts are possible - including attributing malign intent to some or all of the parties, or appealing to some basic aspect of human nature, but I want to suggest that there is something about the nature of politics, particularly democratic politics, that makes such impasses a predictable consequence of real political systems. 
The suggestion is simply that democratic politics (and, perhaps, other forms of politics ${ }^{18}$ ) requires a degree of commitment: that is, governments, parties and politicians have to commit themselves to particular actions and policies with their continuing electoral success depending in large part on their ability to deliver on their commitments. A politics of electoral commitment may work well most of the time; both in restraining the commitments that seekers of political office might enter into, since they will understand that failure to deliver may be costly in electoral terms, and in ensuring that the political process generally delivers on expectations. But commitment is costly, and one of the costs of a politics of electoral commitment is an occasional impasse. The design (or evolution) of a political system might be expected to take account of the trade-off between the benefits and costs of political commitment, but even the optimal balance will imply some cases of political impasse where a solution that may seem feasible in absolute terms is nevertheless institutionally relatively infeasible within the established political framework. Here the issue distinguishing between the absolute and relative notions of feasibility may be only partly epistemic, based in lack of understanding of the full effects and consequences of particular institutional arrangement. But there may be another dimension of the notion of relativity in play here, one that recognizes the necessarily imperfect nature of practical institutions.

We now turn to the topic of the interaction between institutional arrangements and individual motivation and to incentive effects. Institutions do not passively process given individually motivated actions into social outcomes, they influence and select for motivations and potentially create new group agents with what might be termed 'artificial' motivations. For example, a government agency might both create roles (ministers, executive officers) who speak and act on behalf of that agency according to motivations that are largely institutionally defined rather than being the personal motivations of the individual who happen to fill those roles at any given time. 
Such an agency might also use incentive effects to pursue its ends, so that it seeks to bend the motivations of individuals to its purposes. Using carbon taxes to incentivize energy efficiency, or tobacco taxes to reduce smoking are obvious examples, but there are many less obvious but no less significant examples of incentive effects and 'nudges'. ${ }^{19}$

If we were to take an absolute line on feasibility, it might seem that institutional considerations could have relatively little impact on feasibility. The idea of absolute human feasibility would already identify as feasible all outcomes that could be reached if individuals had motivations other than those they actually have, and a similar point would follow in relation to institutional arrangements: states of the world would be categorized as feasible if they could be reached under some institutional arrangement, even if that institutional arrangement was far removed from the arrangement actually in place. Just as well-motivated and fully compliant agents may be expected to act as the relevant normative code requires so well-structured and compliant institutions would operate to work alongside individuals in achieving any desired social outcome that was resource feasible.

However, just as it seems appropriate to take a relative view of resource feasibility, recognizing the epistemic and other limits that determine our current beliefs and understanding of what resources and technologies are available; so it seems appropriate to take a relative view of both human and institutional feasibility and the interaction between the two, recognizing the epistemic and other limits that influence our current motivations and institutional arrangements. This is not to say that the feasible set of motivations and institutional arrangements should be restricted to those motivations and institutions that actually exist. The distinction between static and dynamic understandings of relative feasibility applies in the institutional domain too. So that the dynamic understanding of the relative institutionally feasible set should also include those motivational 
possibilities and institutional arrangements that might realistically be reached by processes of reform starting from the identified status quo. For example, reforming institutional arrangements so as to shift some activity from the public sector to the private sector (or vice versa) might itself be feasible, and such a reform might in turn promote a change in the motivation of agents in relation to that activity via different incentive effects and these changes might interact to bring about a social outcome not accessible under the present institutional regime. That outcome would then be humanly and institutionally feasible in the relative sense even though it is not directly accessible under current institutional and motivational arrangements. In this way the idea of relative feasibility in the resource, human and institutional domains seeks to identify those states that are directly or indirectly attainable from the current reality, and this is surely a realistic sense of feasibility.

Institutions are often designed or reformed to reflect normative beliefs and concerns, or to provide incentives for individuals to act in a manner more closely reflecting prevailing norms. As was the case in the discussion of human feasibility, we should recognize that issues of institutional feasibility are often intertwined with normative issues so that there is no bright line distinguishing issues of desirability from issues of feasibility. The fact that institutions are imperfect normative guides reflects our limited understanding of both the appropriate normative standards and the operating characteristics of alternative institutions.

The presentational structure of this discussion might suggest that the flow from resource to value to human to institutional feasibility is uni-directional. But it should be clear that there are potential feedbacks both in logic and over time. It may be, for example that the institutional arrangements directly influence the state of technology and so affect resource feasibility and therefore value feasibility. In fact we should think about these aspects of feasibility as being organized as a set of 
simultaneous relations - with each depending on the others. Nevertheless, I suggest that it is valuable to identify the aspects of feasibility separately so as to reveal the structure of the interrelationships among the various forms of constraint.

\section{Epistemic Issues}

As we have already seen, epistemic issues arise in relation to each of the identified aspects of feasibility and inform the distinction between absolute and relative notions of feasibility. In the case of resource feasibility, the specification of what is known about the available set of fundamental resources and production techniques is key to locating any practical, relative understanding of resource feasibility. In the case of value feasibility we add in the further element of potential epistemic limitations in relation to values themselves. In the case of human feasibility we add in the issues of motivations that depart, for epistemic or other reasons, from the appropriate normative code as well as potentially divergent and imperfect understandings of that code. When considering institutional feasibility we add epistemic limitation on our knowledge of the operating characteristics of institutions and their incentive effects on agent motivations. With some oversimplification, we might regard resource feasibility to be the realm of science, value feasibility the realm of philosophy and human and institutional feasibility the realm of social science. It might seem, then, that while we can surely distinguish between these aspects of feasibility, it is the epistemic dimension of each of them that plays a key role in illuminating the distinction between absolute and relative understandings of feasibility.

There is an additional linkage or interaction between epistemic concerns and feasibility in that the production, distribution and use of knowledge is itself subject to feasibility constraints. Just as any 
particular pattern of the production, distribution and use of goods and services is subject to the constraint of feasibility, so any particular pattern of epistemic production, distribution and usage must be feasible.

Modelling incomplete information and its implications is a major challenge, and I will simply outline one possible approach that is consistent with the partial separation of incomplete information and uncertainty. ${ }^{20}$ Consider Figure 1 which presents a simplified three dimensional sketch of a complex value function. The basic idea is that society may be analyzed into a large number of 'features' (which reflect resources, technologies, institutions or any other relevant variables) which combine and interact to generate value. For the sake of the discussion here we may think either of a particular value, or of all-things-considered value, without changing the basic point I wish to make. Varying any feature (or set of features) will cause the level of value realized to vary and the overall relationship between the features and value is potentially complex in the sense that the value function may not be smooth, monotonic or single peaked. For ease of presentation, Figure 1 depicts the case in which there are just two relevant features of society, with the value realized by any combination of those two features shown as the 'height' or third dimension represented in the figure. In the surface as drawn there are many local optima, and a clear global optimum. 


\section{Figure 1 Complex Value Surface}

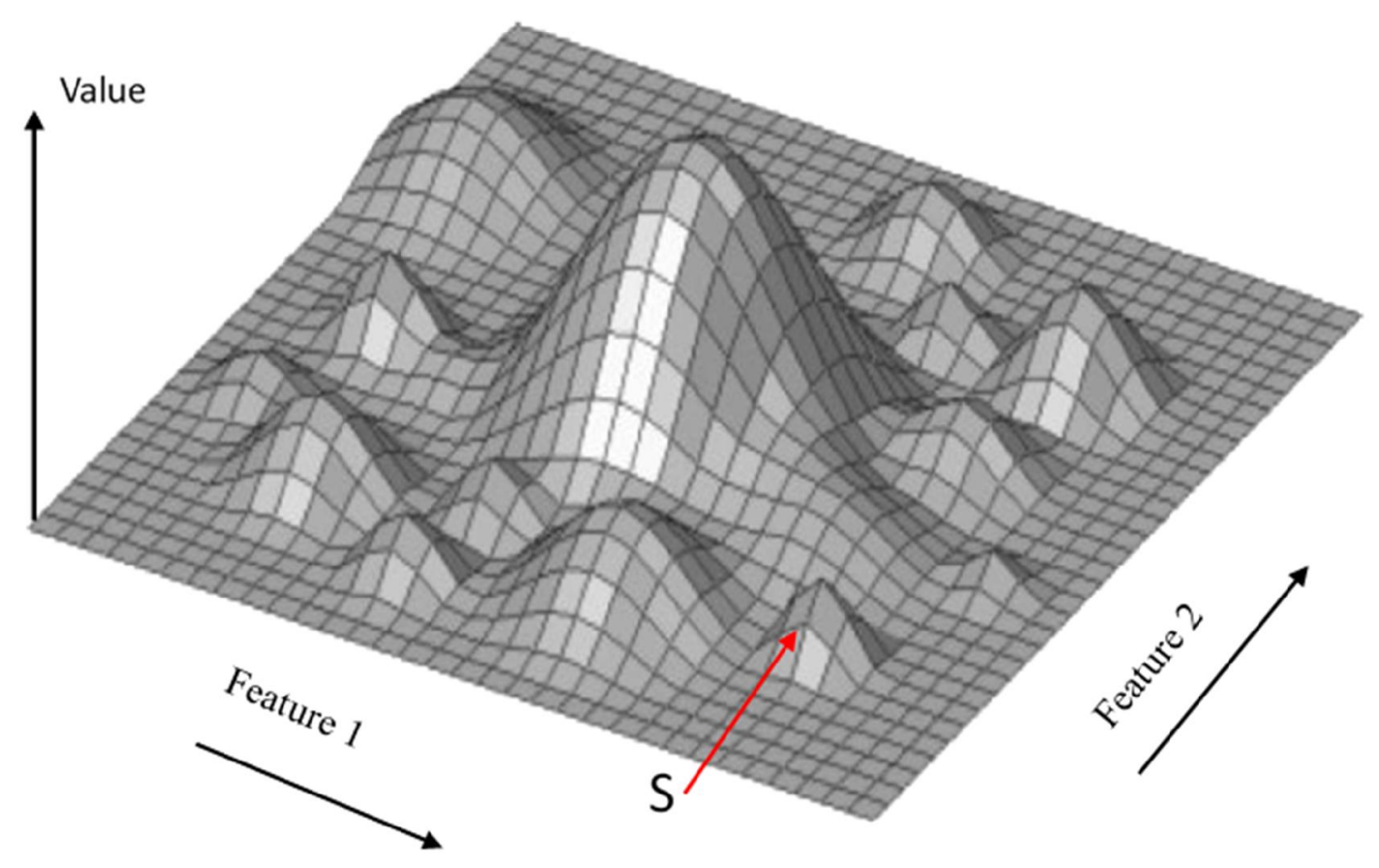

This figure might be understood as representing absolute feasibility. That is, the 'features' collectively exhaust all of the possible information relating to resources, production techniques, motivations and institutions that is consistent with the true laws of science and social science, and the definition and measurement of value is also complete and accurate. Information is complete and perfect and there is no uncertainty. Under these circumstances, realizing any point on the value surface is absolutely feasible and it would seem to be a straightforward matter to plot a course from any point on the surface that might represent the inherited status quo to the global optimum. 
That is, it would be conceptually straightforward to identify the social reforms - interpreted as changes in the underlying 'features' of society - that would, if implemented, bring us to the ideal.

However, we may now introduce the idea of epistemic limitations or incomplete knowledge. One way of doing this is to suggest that our knowledge of society is limited by our current position as indicated by the particular combination of features' that identify the status quo, So that we can only 'know' what lies within a certain range of our present position. ${ }^{21}$ For example, let the point S in Figure 1 represent the status quo, then if the range of our knowledge is tightly circumscribed to the local vicinity of S we might merely perceive the slope of the surface at that point and so move to 'increase' Feature 2 as a means of locally improving value. If our range of knowledge is slightly wider we might perceive a position of greater value nearby and move to adjust features accordingly. But if our range of knowledge were wider still we might conclude that a higher value could be attained by significantly 'reducing' Feature 1 even though, initially, any reduction in Feature 1 would yield a decline in value. The basic point is clear enough, the extent of our information will often dictate both what appears to be the best direction of reform and the best target destination. What is taken to be feasible in the relative sense will impact on our strategy of reform. And this is true without any appeal to uncertainty in the sense of a probabilistic relationship between actions and outcomes. In this simple model everything within the limited range of knowledge might be assumed to be known with certainty, so that all reforms that move from one point to another within the known range have exactly the anticipated effect - there is no risk associated with reform within the range of our knowledge.

If, as a matter of second order knowledge, we understand that we have incomplete information and that moving around the surface can reveal new information, it becomes possible to consider a strategy of exploration: that is, it is feasible to engage in a strategy of varying the features of society 
in order to discover more information about the value surface that we are on, rather than directly to achieve greater value, so as to expand the scope of relative feasibility. This then introduces the idea of uncertainty. If we adopt reforms that take us beyond our known horizon, so as to expand our horizon, we have no accurate basis for predicting the likely outcome in terms of the value that might be associated with the reformed set of features, or what we might learn about the new region of the value surface. ${ }^{22}$

When I say that we have no accurate basis for predicting the likely outcomes of reforms that take us beyond our knowledge horizon, I do not mean to imply that we are incapable of making some prediction; we might assume any number of different things to provide us with some basis for forming expectations. The point is just that such predictions are necessarily uncertain. Optimists will suggest that such 'experiments in living' (to use Mill's phrase) are likely to be progressive in the sense that they reveal ways of improving social arrangements. Pessimists are more likely to invoke arguments of unanticipated consequences and the 'precautionary principle'. ${ }^{23}$

Geoffrey Brennan and I have argued elsewhere that we might understand one form of conservatism by reference to the nature and shape of the value function. ${ }^{24}$ The basic idea is that if the relevant value function is concave, this will imply a status quo bias when faced with uncertain choices in relation to reform. That point carries over, with some modification, to the more complex environment relevant here. In the multi-dimensional setting of many features, it will of course be possible for the value surface to be convex in some dimensions and concave in others, but the point remains, that the shape of the value surface - both locally, where it may be known and more globally where it may only be assumed - will systematically influence the attitude to uncertainty in matters of reform, and so may determine the extent of social experimentation and the prospects for global rather than local optimization. 


\section{Conclusion}

At the outset of this paper I noted the distinction between the conditional probability and restricted possibility accounts of feasibility, I now suggest that the more fine-grained discussion of issues of feasibility offered here reveals that the differences between these accounts are relatively minor. Both offer a view of feasibility that is close to the absolute. Wiens offers several criticisms of the conditional probability account while acknowledging that these criticisms fall short of providing conclusive reasons to reject that account. ${ }^{25}$ In particular Wiens argues that the conditional probability approach excludes motivational issues from the set of constraints. However, as we have seen, Wiens's own discussion of motivational feasibility places him very close to the position adopted by Estlund which disallows claims of motivational infeasibility except in pathological cases.

By discussing the identified aspects of feasibility individually, we can both recognize that different aspects of feasibility generate rather different forms of constraint and that these forms of constraint cut across the distinction between hard and soft constraints. By emphasizing the importance of the co-feasibility of sets of actions supporting social outcomes or states of the world we shift attention from the case by case application of feasibility to a more holistic application that will tend to reveal patterns of infeasibility that might otherwise be obscured. By emphasizing the distinction between absolute and relative feasibility we can shift attention away from feasibility as an abstract and idealized concept and re-connect it with the world as it is.

The key role of motivations is illuminated by the more detailed focus on human feasibility and its connection with the institutional aspect of feasibility. In this way we can agree with Gilabert and 
Lawford-Smith and with Estlund that the lack of appropriate motivation, in itself, may not be a constraint on absolute feasibility, while going beyond Wiens in recognizing that current motivations and the incentive structures associated with current institutional arrangements provide the basis for a more realistic idea of relative feasibility. More generally we can argue, contra Wiens, that recognizing various aspects of feasibility, types of constraint, and degrees of relativity reveals more of the structure of feasibility than treating all constraints by analogy with physical resource constraints.

The approach adopted here also allows us to clarify the extent and nature of the interactions between the realms of feasibility and desirability. It is sometimes assumed that the significance of the emphasis on matters of feasibility depends on a strong form of separability between the feasible and the desirable, such that the feasible set can be defined in terms that make no reference to normative consideration, with normative criteria then introduced to select from that feasible set. This assumption is indirectly supported by reference to the standard economists' distinction between the production possibility frontier and welfare criteria which does exhibit this form of separability. While the discussion here retains the idea that the simple notion of resource feasibility can be portrayed as independent of normative considerations, all of the other aspects of feasibility discussed here involve at least some reference to normative considerations. This is most obvious (and uncontroversial) in the case of value feasibility, but issues surrounding normative motivations and institutional agency also mix facts with values in generating statements of feasibility.

I have done no more than sketch the outlines of the four identified aspects of feasibility and their inter-relations, I hope that the nature of the discussion has underlined the point I made at the outset that these are not intended as alternative conceptualizations of feasibility: each of the four identified aspects contributes to the whole. But I also hope that the identification of these four 
aspects of feasibility, together with the discussion of the distinction between absolute and relative feasibility, provides a more nuanced and detailed understanding of the complexity of the idea of feasibility than is provided by either the conditional probability or the restricted possibility account of feasibility, not least by pointing out that no single aspect provides a good basis for a general idea of feasibility.

In recognizing these four aspects of feasibility I suggest that statements regarding the alleged feasibility (or infeasibility) of any particular action, outcome or state of the world need to be relatively complex and nuanced statements, with a clear specification of whether they are intended as absolute or relative statements. Thus state of the world X might be resource feasible on the basis of current knowledge, while posing a challenge to institutional feasibility if we have no clear understanding of a workable institutional structure that will realize $\mathrm{X}$ with high probability given individual motivations as they are. Or again, the realization of some combination of goals may raise quite separate issues of value feasibility and institutional feasibility in either the absolute or relative cases. Allowing for this richer texture of the idea of feasibility is, I believe, an important part of the more general idea of taking feasibility seriously. 


\section{NOTES}

${ }^{1}$ See, for example, Juha Räikkä, "The Feasibility Condition in Political Theory," Journal of Political Philosophy 6, no. 1 (1998):27-40, Geoffrey Brennan and Philip Pettit, "The Feasibility Issue," in The Oxford Handbook of Contemporary Philosophy, ed. Frank Jackson and Michael Smith (Oxford: Oxford University Press, 2005), Geoffrey Brennan and Nicholas Southwood, "Feasibility in Action and Attitude," in Hommage à Wlodek. Philosophical Papers Dedicated to Wlodek Rabinowicz (http://www.fil.lu.se/hommageawlodek/site/paper/Brennan\&Southwood.pdf: 2007), Tyler Cowen, "The Importance of Defining the Feasible Set," Economics and Philosophy 23, no. 1 (2007):1-14, Pablo Gilabert and Holly Lawford Smith, "Political Feasibility: A Conceptual Exploration," Political Studies (2012):809-25, Geoffrey Brennan, "Feasilbilty in Optimizing Ethics," Social Philosophy and Policy 30, no. 1-2 (2013):314-29, Holly LawfordSmith, "Understanding Political Feasibility," Journal of Political Philosophy 21, no. 3 (2013):243-59, Pablo Gilabert, "Justice and Feasibility: A Dynamic Approach," in Political Utopias: Contemporary Debates, ed. Kevin Vallier and Michael Weber (Oxford: Oxford University Press, 2017), David Wiens, "Political Ideals and the Feasibility Frontier," Economics and Philosophy 31, no. 3 (2015):447-77.

${ }^{2}$ Particularly, Brennan and Southwood, "Feasibility in Action and Attitude.", Gilabert and Lawford Smith, "Political Feasibility: A Conceptual Exploration.", Lawford-Smith, "Understanding Political Feasibility.", Gilabert, "Justice and Feasibility: A Dynamic Approach."

${ }^{3}$ Wiens, "Political Ideals and the Feasibility Frontier."

${ }^{4}$ In this section, resources are interpreted as non-human resources - I return to consider human resources and motivations in section 4 below.

${ }^{5}$ Gilabert, "Justice and Feasibility: A Dynamic Approach." focuses attention on dynamic feasibility and the 'dynamic duties' that arise. 
${ }^{6}$ Wiens, "Political Ideals and the Feasibility Frontier." 'Everything' here includes all those issues that I include under human and institutional factors in addition to non-human resources and technology.

${ }^{7}$ See, for example, Michael Stocker, Plural and Conflicting Values (Oxford: Clarendon, 1990), William Galston, Liberal Pluralism: The Implications of Value Pluralism for Political Theory and Practice (Cambridge: Cambridge University Press, 2002). The idea of value feasibility is employed in Alan Hamlin and Zofia Stemplowska, "Theory, Ideal Theory and the Theory of Ideals," Political Studies Review 10, no. 1 (2012):48-62.

${ }^{8}$ David Estlund, "Human Nature and the Limits (If Any) of Political Philosophy," Philosophy \& Public Affairs 39, no. 3 (2011):207-37, David Wiens, "Motivational Limitations on the Demands of Justice," European Journal of Political Theory 15, no. 3 (2016):333-52, David Estlund, "Reply to Wiens," European Journal of Political Theory 15, no. 3 (2016):353-62.

${ }^{9}$ Estlund's discussion is explicitly concerned with motivational capacities rather than motivational feasibility, but his question concerns whether any motivational incapacity should count as a (feasibility) constraint on morality.

${ }^{10}$ See Gilabert and Lawford Smith, "Political Feasibility: A Conceptual Exploration." p812.

${ }^{11}$ For detailed accounts of current approaches to group agency see Christian List and Philip Pettit, Group Agency: The Possibility, Design, and Status of Corporate Agents (Oxford University Press Oxford, 2011), Raimo Tuomela, Social Ontology: Collective Intentionality and Group Agents (Oxford University Press, 2013). List and Pettit identify three conditions for a group to be an agent, the group must: (1) hold 'beliefs' or 'representational states' relating to the environment in which it operates, (2) hold 'desires' or 'motivational states' relating to features of its environment, and (3) have a capacity to 'act' in the environment in pursuit of its desires.

12 Patrick Tomlin, "Should We Be Utopophobes About Democracy in Particular?," Political Studies Review 10, no. 1 (2012):36-47. Especially pp.43-44. 
${ }^{13}$ Although Wiens criticizes Gilabert and Lawford-Smith in relation to their position, I suggest that his position - as evidenced in the discussion with Estlund - is quite similar.

${ }^{14}$ For a simple account of the fundamental welfare theorem see Francis M. Bator, "The Simple Analytics of Welfare Maximization," The American Economic Review 47, no. 1 (1957):22-59.

${ }^{15}$ Ludwig Von Mises, Economic Calculation in the Socialist Commonwealth (Ludwig von Mises Institute, 1990). Friedrich August von Hayek, "The Use of Knowledge in Society," American Economic Review XXXV, no. 4 (1945):519-30.

${ }^{16}$ Mark Pennington, "Robust Political Economy and the Priority of Markets," Social Philoosophy and Policy (Forthcoming).

${ }^{17}$ A similar point is made by Räikkä, "The Feasibility Condition in Political Theory."

${ }^{18}$ I focus here on the role of electoral commitments in democratic politics, other forms of politics may require other forms of commitment and may also generate political impasses.

${ }^{19}$ For a discussion of incentive effects see Uri Gneezy, Stephan Meier, and Pedro Rey-Biel, "When and Why Incentives (Don't) Work to Modify Behavior," The Journal of Economic Perspectives (2011):191-209. For discussion of 'nudge' based strategies see Peter John et al., Nudge, Nudge, Think, Think: Experimenting with Ways to Change Civic Behaviour (London: Bloomsbury Academic, 2011).

${ }^{20}$ This sketch owes much to conversations with Jerry Gaus. See Gerald F Gaus, "The Evolution, Evaluation and Reform of Social Morality: A Hayekian Analysis," in Hayek and the Modern Economy, ed. David M. Levy, Peart, Sandra (New York: Palgrave Macmillan, 2013), Gerald F Gaus, "The Role of Conservatism in Securing and Maintaining Just Moral Constitutions: Toward a Theory of Complex Normative Systems," in Nomos L V I: American Conservative Thought, ed. Sanford V Levinson, Joel Parker, and Melissa S Williams (New York: New York University Press, 2016). 
${ }^{21}$ For the purposes of this illustrative discussion I abstract from any issues relating to the distribution of the relevant knowledge within society and its impact on individual and collective decision making.

${ }^{22}$ Note that I assume that the definition and measurement of value are constant throughout. If moving around the surface causes us to re-define value or re-evaluate all potential points in the landscape, so that morality is endogenous with respect to features, the model becomes more complex and may become chaotic.

${ }^{23}$ For a critical discussion of the precautionary principle see Cass R. Sunstein, Laws of Fear: Beyond the Precautionary Principle (Cambridge: Cambridge University Press, 2005).

${ }^{24}$ See Geoffrey Brennan and Alan Hamlin, "Analytic Conservatism," British Journal of Political Science 34 (2004):675-91, Geoffrey Brennan and Alan Hamlin, "Conservatism, Idealism and Cardinality," Analysis 66, no. 4 (2006):286-95, Geoffrey Brennan and Alan Hamlin, "Conservatism and Radicalism," Constitutional Political Economy 24, no. 2 (2013):173-76.

${ }^{25}$ Wiens, "Political Ideals and the Feasibility Frontier." pp 451-2. 